Purchasing for Quality: the Providers' View

\title{
Rehabilitation for people with chronic lung disease
}

\author{
Michael D L Morgan, Frances H Quirk, Sally J Singh
}

Chronic lung disease, particularly chronic airflow limitation (COPD), is a major burden on the resources of the health service. In the United Kingdom chronic obstructive lung diseases will account for about 6600 hospital bed days and 19000 general practitioner consultations in an average district. There are 26000 deaths a year from chronic airflow limitation in England and Wales. ${ }^{1}$ The conventional medical treatment of established chronic airflow limitation is often disappointing and limited to the recovery of some lung function by use of bronchodilators and steroids and retarding of further decline by smoking cessation and domicillary oxygen. Impairment of lung function (for example, forced expiratory volume in one second $\left(\mathrm{FEV}_{1}\right)$ ) occurs early in chronic airflow limitation and declines linearly with age and smoking exposure. The impact of the reduction of $\mathrm{FEV}_{1}$ is not immediately obvious and the disability that results from chronic airflow limitation may not become noticeable until $60 \%$ of $\mathrm{FEV}_{1}$ is lost. However, once chronic lung disease begins to interfere with daily domestic function it is already too advanced to expect major improvements from conventional medical treatment. The physical disability that results from chronic airflow limitation is also compounded by other factors such as immobility, loss of physical fitness, and social isolation. Since chronic airflow limitation occurs more commonly in social classes 4 and 5, the physical handicap imposed by the disease will usually result in the loss of manual employment and further economic disadvantage.

Rehabilitation begins with the assumption that the underlying condition cannot be improved further by medical management and seeks to maximise the functional and psychosocial ability of the patient. Clinical guidelines which are becoming available for managing chronic airflow limitation include recommendations for rehabilitation for patients with chronic lung disease to improve their functional capacity and independence. ${ }^{2}$ This article will outline the components and practice of pulmonary rehabilitation and describe what is known about the objective and economic benefits of the process. It will be based as far as possible on the evidence of randomised and controlled clinical trials.
Goals of pulmonary rehabilitation

Reduction in symptoms

Improved functional capacity

Reduced hospital attendance

Independence in daily life

What pulmonary rehabilitation cannot expect to improve

Longevity

Lung function

Respiratory failure

What is pulmonary rehabilitation?

Most clinicians unwittingly provide some form of rehabilitation in the form of encouragement or practical advice. The scientific foundations of pulmonary rehabilitation were sown in the United States in the postwar years, initially in response to tuberculosis and subsequently with chronic airflow limitation. This work culminated in a definition of pulmonary rehabilitation and guidelines for practice. ${ }^{3}$ Recently, these guidelines have been updated with research based evidence and a new, less cumbersome, definition. ${ }^{4}$ The most recent development has been the acknowledgement by the National Institutes of Health, that pulmonary rehabilitation has a central role and an agenda for scientific research. ${ }^{5}$ Pulmonary rehabilitation has been practised enthusiastically in the United States and to a lesser extent in continental Europe. In Great Britain it has, until recently, been viewed with some sceptism and provision has been poor. The reasons for this disparity are not clear, but the consumer pressure that has always been present in North America has not had much influence in the United Kingdom until recently. Also, British clinicians have not been impressed by the more observational nature of early research. However, the emergence of good quality, randomised controlled trials and consumer pressure should redress the balance.

STRUCTURE AND COMPONENTS OF PULMONARY REHABILITATION

The process of pulmonary rehabilitation may seem to vary widely from programme to programme. Some programmes are constructed around inpatient admission, others are outpatient or even home based. Nevertheless, 
most programmes have common principles. The process of rehabilitation usually includes elements of exercise conditioning, together with disease education and psychosocial support. It is a principle of pulmonary rehabilitation that these elements are delivered by individual prescription through a multidisciplinary team, usually headed by a respiratory physician and a physiotherapist with help from occupational therapists, clinical psychologists, nurses, technicians, and others with legitimate contributions. Many of these skills are already available in district general hospitals and require only coordination. In the United Kingdom a few programmes have now been established, primarily as outpatient schemes. These are generally structured as two to three hour sessions, two to three times a week for about six to eight weeks. During attendance patients undergo exercise conditioning and then have a session related to education or small group interaction. Examples of the types of exercise training include aerobic activity such as brisk walking, strength or upper body exercises, and possibly respiratory muscle training. It is important to remember that each level of exercise should have been individually prescribed even if it takes place in a group setting. Patients with chronic airflow limitation may be able to train at a higher percentage of $\dot{\mathrm{V}} \mathrm{O}_{2} \mathrm{MAX}$ (maximal oxygen uptake) than normal or athletic subjects. ${ }^{6}$ Suitable subjects for education and psychosocial support include disease education, nebuliser and oxygen advice, relaxation, physiotherapy, nutrition, smoking cessation, coping skills, and advice on benefits. Including smoking cessation classes at this stage is controversial. By the time that most patients have become disabled by lung disease they have already given up smoking and do not like to be publicly reminded of their misdemeanour in the setting of the rehabilitation class. Those patients who are still smoking need to be given individual confidential counselling. The place for mass education regarding smoking should be at a much earlier stage in the natural history of chronic airflow limitation.

CANDIDATE SELECTION AND ASSESSMENT Although the details of individual programmes may vary, there are fundamental procedures to all programmes. These include selection, assessment, rehabilitation, evaluation, and follow up. A formal selection procedure is important for several reasons. Assessment of motivation is critical because resources are scarce and drop outs from a programme are individually unsatisfactory and also have a dispiriting effect on the group. Selection may be achieved informally by interview or by psychological profile. The range of patients who have been shown to benefit from rehabilitation is wide, and all ages of patients and degrees of severity of disease can be considered. ${ }^{7}$ Even patients receiving long term oxygen therapy may be suitable. However, in those programmes which have cohort classes it is important to group together people of similar ability so that none are discouraged by the performance of others.

Components of and contributors to
pulmonary rehabilitation ${ }^{\star}$
Components
Exercise training:
Aerobic (brisk walking, cycling)
Strength
Respiratory muscle
Disease education:
Pathology
Management
Physiotherapy
Relaxation
Coping skills
Drugs
Devices/oxygen
Smoking cessation
Sexual relations
Contributors
Coordinator
Doctor
Physiotherapist
Occupational therapist
Dietitian
Psychologist
Technician
Pharmacist
Self help group member
Social worker
Nurse
^Activities may occur in a group setting but the
exercise training and some education
components will be individually prescribed after
assessment. The contributions from health
professionals need be only on a sessional basis,
provided that a coordinator is available to
oversee the programme.

Assessment before rehabilitation is important so that progress can be judged. This usually takes the form of a measure of disability (functional performance) and an assessment of handicap (quality of life). These are repeated at the end of the course to evaluate the programme. Most programmes have a finite end or a graduation. In the United States patients commonly continue rehabilitation indefinitely, but this runs the risk of overloading the courses and producing dependence. It is also rather brutal to discharge patients abruptly at the end of the course. An intermediate path would be to provide an occasional review or to encourage participation in local or national self help groups such as Breathe Easy.

\section{Assessment of outcome}

Pulmonary rehabilitation, like rehabilitation in general, accepts that patients have an impairment of physiological capacity which may not be capable of correction. It seeks to develop those aspects of disability and social functioning that can improve functional capacity. In the context of lung disease it is therefore unreasonable to expect improvements in measures of impairment such as $\mathrm{FEV}_{1}$, blood gas tensions, or even maximal exercise capacity from pulmonary rehabilitation. Assessing patients with chronic lung disease has to be more sophisticated and focused on function. In practice this means making an estimate of 
disability through an exercise test and some estimate of handicap through a quality of life measure.

\section{DISABILITY}

Disability is related to exercise performance and can be assessed in the laboratory and in the field. There is however some lack of clarity regarding the definition of disability in patients with lung disease. An impairment is defined as a functional or physiological limitation such as reduced $\mathrm{FEV}_{1}$ or maximal oxygen uptake during exercise. Disability is defined as the restriction of activity that results from the impairment. Obviously, with lung disease, the question as to whether a submaximal exercise test result reflects impairment or disability is debatable. Nevertheless, a reduction in exercise tolerance is likely to be associated with reduction in functional ability, and a suitable exercise test can be a useful reflection of functional capacity.

Laboratory exercise tests are usually performed on a treadmill or cycle ergometer with a symptom limited maximal or steady state submaximal protocol. Maximal capacity (usually expressed as maximal oxygen uptake, $\mathrm{Vo}_{2} \mathrm{MAX}$ ) is limited in health by oxygen delivery to respiring muscle and not by the lungs. In lung disease the abnormal pulmonary mechanics impose a premature threshold on maximal oxygen uptake which is unlikely to be improved by rehabilitation. Since most people do not stress themselves to this degree in daily life a submaximal exercise test or endurance capacity is probably more relevant and these tests examine the functional utilisation of capacity. In rehabilitation, exercise tests have to be practical and possible to perform in a group setting. For this reason field walking tests are useful for assessment and evaluation. Examples include the shuttle walk and the six minute walk test. ${ }^{89}$ (The six minute walk test is a self paced corridor walking test in which subjects are invited to walk as far as they can in six minutes, usually along a hospital corridor.)

\section{QUALITY OF LIFE}

Evaluating the impact of a multidisciplinary intervention, such as pulmonary rehabilitation, on quality of life is particularly relevant in a group of patients in whom pharmacological treatment has been optimised and little direct physiological improvement is likely. Demonstrating the efficacy of a programme to improve patients' quality of life is generally by the application of a "pen and paper" instrument designed to quantify and be sensitive to the construct of health related quality of life, either in general or specifically for lung disease. The short form 36 (SF36) and the sickness impact profile have both been applied to evaluating pulmonary rehabilitation, although their generality may reduce their sensitivity to change. ${ }^{10}$ The chronic respiratory disease questionnaire (CRDQ), a disease specific instrument, was developed as an outcome measure for clinical trials and validated in a pulmonary rehabilitation setting. ${ }^{11}$ The four components of the questionnaire have considerable face validity with respect to the proposed benefits of pulmonary rehabilitation; scores are derived for shortness of breath, emotion, mastery, and fatigue. Although this questionnaire has been applied with the most frequency, other instruments have also received attention: the breathing problems questionnaire, ${ }^{12}$ the $\mathrm{St}$ George's questionnaire, ${ }^{13}$ and the quality of wellbeing scale. ${ }^{14}$ Quality of life is a legitimate and necessary topic of assessment but as yet there is no perfect measure that meets every requirement of clinicians, scientists, and patients. The ideal quality of life instruments would be short; would produce a single score in meaningful units; would have demonstrable validity, reliability, and sensitivity in the setting of pulmonary rehabilitation; and would have comparative properties to facilitate cost-benefit analysis and health policy decision making. Since there is not yet an ideal questionnaire providers will need to decide between sensitivity (chronic respiratory disease questionnaire) and ease of administration (St George's and breathing problems questionnaires).

\section{Evidence for effectiveness of pulmonary rehabilitation}

The results of early pulmonary rehabilitation programmes were often deemed to be disappointing because they do not fundamentally alter the course of the disease. Also, there have been relatively few randomised controlled studies which examine the outcome with any sensitivity. As stated previously, pulmonary rehabilitation cannot expect to modify the physiological impairment of airway calibre, gas exchange, or maximal oxygen uptake but we now realise that it is still possible to achieve useful improvements in functional capacity and genuine health gain.

\section{Proved benefits of pulmonary rehabilitation \\ Exercise capacity improved in: \\ Walking tests \\ Submaximal treadmill tests \\ Maximal exercise performance (occasionally) \\ Symptoms and quality in life \\ Reduced shortness of breath on exercise \\ Improved general health scores \\ Improved disease specific questionnaire scores \\ Economic \\ Improved independence (activities of daily living) Reduced hospital admission \\ Reduced clinic attendance}

\section{MORTALITY}

Mortality in chronic airflow limitation is closely and inversely correlated with $\mathrm{FEV}_{1}$, and therefore pulmonary rehabilitation would not expect to make much impact on mortality. However, occasionally a covert bronchodilator or steroid response may have been disclosed during the programme. There are also large difficulties in constructing a prolonged controlled trial to show the effect. Some studies have made 
comparisons with population controls and may show some small benefit of longevity. Comparisons of survival curves of different programmes are heavily influenced by selection bias. ${ }^{15}$ It is important to realise that increasing the length of life is not an aim of rehabilitation; it is more important to improve the quality of the remaining years of life.

EXERCISE PERFORMANCE

As expected, pulmonary rehabilitation does not result in consistent improvements in static pulmonary function. Several randomised, controlled studies have failed to show improvements in spirometry or gas exchange in spite of demonstrable improvements in exercise capacity. ${ }^{16-18}$ One of the difficulties of appraising the results of rehabilitation is the inability to separate the effects of the different elements of the programme with any confidence. However, the separate effect of exercise training and rehabilitation has been examined reasonably closely. These studies, predominantly with aerobic type exercise, showed that improvements can be achieved in walking test performance, submaximal testing, and occasionally in maximal testing. ${ }^{19-21}$ However modest these improvements may seem it is important to remember that in these patients even maintaining stability could be considered to be successful.

Other types of exercise training have also been studied. Significant benefits seem to be associated with strength building exercises. ${ }^{22}{ }^{23}$ However, the role of inspiratory muscle training is less clear, seeming, superficially, to be an appropriate treatment, although this is not supported by the available evidence. ${ }^{24} 25$ Training for inspiratory muscle strength or endurance seems to be task specific, and the effect does not extend to improvements in whole body performance or quality of life. It cannot therefore be currently recommended as a useful component of rehabilitation, although some recent work suggests that it may augment the effect of aerobic cycle training. ${ }^{26}$

SYMPTOMS AND QUALITY OF LIFE

For individual patients the benefits of pulmonary rehabilitation will be reduced symptoms, improved functional capacity, and independence in daily life. Recent evidence suggests that symptoms and subjective measures of shortness of breath are more closely related to functional ability than to conventional physiological parameters. ${ }^{27}$ The social consequences of deteriorating lung disease are also more important determinants of disability than the disturbance of physiology. ${ }^{28}$ Therefore studies which have shown improvements in symptoms, coping skills, self esteem, or quality of life have important implications.

Pulmonary rehabilitation reduces the sensation of shortness of breath on exercise through desensitisation or efficiency of exercise. $^{29}{ }^{30}$ Whether this is due to the effect of exercise training or a change in perception brought about by a reduction in anxiety or improvement in self efficacy is not clear. It is likely that patients are simply desensitised to shortness of breath through the confidence of exercising under supervision. ${ }^{31}$ Quality of life measures seem to be consistently improved by most forms of pulmonary rehabilitation. Improvements have been shown in scores for shortness of breath ${ }^{32}$ and in general health ${ }^{33}$ and disease specific questionnaires. ${ }^{20}{ }^{21}$ Psychosocial intervention of any kind seems to improve social function, and intervention by rehabilitation or self help groups can reduce the frequency of hospital admissions. ${ }^{34}$ The ease of achieving this improvement illustrates how easy it is to improve patients' lives simply by taking an interest. In some studies the psychological measures have improved in the control groups without a parallel change in performance. ${ }^{16}$ Interestingly, in some published studies, as well as our own experience, the improvements in exercise performance do not necessarily relate to the change in quality of life measures. ${ }^{20} 35$

\section{ECONOMIC BENEFITS}

Chronic lung disease usually afflicts people in later life and results in increasing disability, dependence, and frequency of hospital admissions. The effect of the disease is also felt by family or carers and places an unknown burden on the community. The purpose of pulmonary rehabilitation is not to prolong life but to sustain independence and reduce healthcare expenditure. The evidence for the effectiveness of rehabilitation has emanated from the United States, where the financial penalties for illness and hospital admission may be large. Pulmonary rehabilitation is recognised for reimbursement by insurers because published evidence illustrates that rehabilitation is effective in substantially reducing acute hospital admissions and other medical costs. ${ }^{36}$ Until recently no motivation has existed in the United Kingdom to reduce acute hospital admissions for chronic airflow limitation, but the introduction of total locality purchasing may well instigate a change in emphasis.

The cost of pulmonary rehabilitation depends on the type of service offered. Inpatient rehabilitation is clearly expensive (\$C 12 000) and is not practised in the United Kingdom. However, short term outpatient, or even community based, rehabilitation may be equally effective, even though the costs are not stated. In all three modes of rehabilitation the beneficial effects are present for at least six months and could be sustained by a minimum level of maintainence support. From our own experience the approximate cost (for a physiotherapist) of a seven week outpatient programme is $£ 250$ per patient, which could be set against the cost of even one hospital admission.

\section{Conclusions}

Pulmonary rehabilitation is beginning to receive the attention it deserves. The increase in healthcare costs and the response to consumer preference has begun to stimulate an interest in this aspect of treatment, coincident with the scientific development of more appropriate outcome measures and a clearer 
understanding of the nature of disability in chronic lung disease. Pulmonary rehabilitation programmes which contain exercise training and psychosocial interventions are effective in producing improvements in physical functioning and quality of life measures. Programmes can be provided in a hospital outpatient or community setting. Although most applicable to patients with chronic airflow obstruction, pulmonary rehabilitation may also benefit other patients with less common conditions. The economic evidence supports the view that effective pulmonary rehabilitation can be inexpensive and provide genuine health gain.

1 Strachan DP. Epidemiology: a British perspective. In: Calverley P, Pride N, eds. Chronic obstructive pulmonary disease. London: Chapman and Hall, 1995.

2 Ferguson GT, Cherniak RM. Management of chronic obstructive pulmonary disease. $N$ Engl f Med 1993; 328:1017-22.

3 American Thoracic Society. Pulmonary rehabilitation. Am Rev Respir Dis 1981;124:663-6.

4 Ries AL. Position paper of the American Association of Cardiovascular and Pulmonary Rehabilitation: scientific basis of pulmonary rehabilitation. Fournal of Cardiopulmonary Rehabilitation 1990;10:418-41.

5 Fishman AP. Pulmonary rehabilitation research. American fournal of Respiratory and Critical Care Medicine 1994; 49:825-33.

6 Punzal PA, Ries AL, Kaplan RM, Prewitt LM. Maximum intensity exercise training in patients with chronic obstructive pulmonary disease. Chest 1991;100:618-23.

7 Niederman MS, Clemente PH, Fein AM, Feinsilver SH, Robinson DA, Ilowite JS, et al. Benefits of a multidisciplinary pulmonary rehabilitation program. Chest 1991;99:798-804.

8 Singh SJ, Morgan MDL, Scott S, Walters D, Hardman AE Development of a shuttle walking test of disability in Development of a shuttle walking test of disability in patients with

9 Butland RJA, Pang J, Gross ER, Woodcock AA Geddes DM. Two, six, and twelve minute walking test in respiratory disease. $B M \mathcal{F}$ 1982;284:1607-8.

10 Ware JE, Sherbourne CD. The MOS 36 item short form health survey (SF36). Med Care 1992;30:473-83.

11 Guyatt G, Townsend M, Berman LB, Pugsley SO. Quality of life in patients with chronic airflow limitation. $B r \mathcal{F} D$ Chest 1987;45:45-54.

12 Hyland M, Bott J, Singh SJ, Kenyon CAP. Domains, constructs and the development of the breathing problems questionnaire. Quality of Life Research 1994;3: problem

13 Jones PW, Quirk FH, Baveystock CM. The St George's respiratory questionnaire. Resp Med 1991;85:25-31.

14 Kaplan RM, Atkins CJ, Timms R. Validity of a quality of wellbeing scale as an outcome measure in chronic obstructive pulmonary disease. Fournal of Chronic Diseases 1984;37:85-95.

15 Petty TL. Pulmonary rehabilitation in perspective: historical roots, present status, and future projections. Thorax 1993;48:855-62.
16 Cockcroft A, Berry G, Brown EB, Exall C. Psychological changes during a controlled trial of rehabilitation in chronic respiratory disability. Thorax 1982;37:413-6.

17 McGavin CR, Gupta SP, Lloyd EL, McHardy GJR. Physical rehabilitation for the chronic bronchitic: results of a controlled trial of exercises in the home. Thorax 1977;32:307-11.

18 Chester EH, Belman MJ, Bahler RC. Multidisciplinary treatment of chronic pulmonary insufficiency. 3. The effect of physical training on cardiopulmonary performance in patients with chronic obstructive pulmonary disease. Chest 1977;72:695-702

19 Toshima MT, Kaplan RM, Ries AL. Experimental evaluation of rehabilitation in chronic obstructive pulmonary disease: short term effects on exercise endurance and health status. Health Psychol 1990;9:237-52.

20 Wijkstra PJ, Van Altena R, Kraan J, Otten V, Postma DS Koeter GH. Quality of life in patients with chronic obstructive disease improves after rehabilitation at home. Eur Respir ₹ 1994;7:269-73.

21 Goldstein RS, Gort EH, Stubbing D, Avendano MA, Guyatt GH. Randomised controlled trial of respiratory rehabilitation. Lancet 1994;344:1394-7.

22 Lake FR, Henderson K, Briffa T, Openshaw J, Musk AW Upper-limb and lower-limb exercise training in patients with chronic airflow obstruction. Chest 1990;97: 1077-82.

23 Simpson K, Killian K, McCartney N, Stubbing DG, Jones NL. Randomised controlled trial of weightlifting exercise in patients with chronic airflow limitation. Thorax 1992;47:70-5.

24 Goldstein RS. Ventilatory muscle training. Thorax 1993;48: 025-33.

25 Smith K, Cook D, Guyatt GH, Madhavan J, Oxman AD. Respiratory muscle training in chronic airflow limitation Respiratory muscle training in chronic airfow limitation

26 Wanke T, Formanek D, Lahrmann H, Brath H, Wild M Wagner Ch, et al. Effects of combined inspiratory muscle and cycle ergometer training on exercise performance in patients with COPD. Eur Respir f 1994;7:2205-11.

27 Wegner RE, Jorres RA, Kirsten DK, Magnussen H. Factor analysis of exercise capacity, dyspnoea ratings, and lung function in patients with severe COPD. Eur Respir $尹$ 1994;7:725-9.

28 Williams, Simon J. Chronic respiratory illness. London: Routledge, 1993.

29 Strijbos JH, Koeter GH, Meinesz AF. Home care rehabilitation and perception of dyspnoea in chronic rehstictive pulmonary disease. Chest 1990;97:109-10S.

30 Reardon J, Awad E, Normandin E, et al. The effect of comprehensive outpatient pulmonary rehabilitation on comprehensive outpatient pulmonary

31 Belman MJ, Brooks LR, Ross DJ, Mohsenifar Z. The variability of breathlessness measurement in patients with chronic obstructive pulmonary disease. Chest 1991;99: 566-71.

32 Mall RW, Medeiros M. Objective evaluation of results of a pulmonary rehabilitation programme in a community hospital. Chest 1988;94:1156-60.

33 Atkins CJ, Kaplan RM, Timms RM, Reinsch S, Lofback K Behavioural exercise programmes in the management of chronic obstructive pulmonary disease. $₹$ Consult Clin Psychol 1984;52:591-603.

34 Jensen PS. Risk, protective factors and supportive interventions in chronic airway obstruction. Arch Gen ventions in chronic airway

35 Readon J, Patel K, Zuwallack RL. Improvement in quality of life is unrelated to improvement in exercise endurance after outpatient pulmonary rehabilitation. fournal of Cardiopulmonary Rehabilitation 1993;13:51-4

36 Toevs CD, Kaplan RM, Atkins CJ. The costs and effects of behavioural programmes in chronic obstructive pulmonary disease. Med Care 1984;22:1088-1100. 